\title{
fragmentos [vestígios] memoriais de performances nos museus 1
}

\section{Anna Paula da Silva}

O objeto de estudo aqui proposto é a compreensão da institucionalização, presença e ausência, de obras de performance nos museus. Fundamentalmente, 0 interesse recai sobre a memória de obras adquiridas por instituições museológicas, o seu acontecimento e, possivelmente, a sua (re)constituição a partir dos vestígios concepcionais pela poética dos artistas e dos registros oriundos da produção documental das instituições: vestígios que declaram a duração no tempo-espaço e possibilidades comunicacionais pós-acontecimento.

Esta proposta visa estabelecer reflexões sobre a produção artística e sua reverberação em instituições museológicas, bem como sobre a performance como transgressora da materialidade e da duração e tem como objetivo o diálogo entre conceitos e definições sobre memória, tempo e performance relacionadas a obras institucionalizadas; a análise da pluralidade de vestígios memoriais; e, a constituição de narrativas a partir desses vestígios, assim como a recepção do público diante obras institucionalizadas.

Para tanto, pretende-se realizar revisão teórica sobre performance, memória/esquecimento, tempo; pesquisa de campo e documental em instituições nacionais e internacionais; entrevistas com profissionais

Este artigo apresenta, de forma modificada, o pré-projeto de pesquisa submetido para seleção de candidatos para o Doutorado Acadêmico em Arte na linha de pesquisa Teoria e História da Arte do Programa de Pós-Graduação em Arte do Departamento de Artes Visuais da Universidade de Brasília. 
de museus, artistas e coletivos para o desenvolvimento de análises sobre aquisições e institucionalizações de performances nos museus a partir dos vestígios oriundos da produção artística e dos registros realizados na documentação museológica das instituições.

As ações singulares de performances e a pluralidade das formas de acontecimento das obras apresentam reflexões sobre a imprevisibilidade da linguagem e os desafios aos museus. Este lugar é confrontado a repensar suas práticas perenes e constituir narrativas sobre a transitoriedade - e/ou a efemeridade - a partir da preservação de fragmentos de obras e realização de registros que narram a temporalidade das performances e arquivam vestígios sobre a produção artística, contribuindo para o desenvolvimento da história da arte, da museologia e de outros campos do conhecimento, de modo a selecionar e partilhar memórias que conectam o público às obras pela assimilação da intangibilidade diante os vestígios memoriais.

Justificativa

Os museus são espaços marcados por ideias perenes, cujas tangibilidades e intangibilidades reverberam na produção de narrativas de memórias e esquecimentos representativos a indivíduos e grupos sociais e sua (re)apresentação a diferentes públicos. Estas dinâmicas colocam em questão $\circ$ tempo e a legitimação de culturas, de prática de temporalidades.

A perenidade é parte dos discursos institucionais de preservação de acervos museológicos. Nesta proposta o seu caráter de perpetuação da eternidade é questionado a partir do caráter transitório das coisas e das escolhas institucionais sob as narrativas, seja nas (re)leituras do museu; nos aspectos ficcionais construídos por meio dos vestígios; e, na recepção de obras de arte. Neste sentido, as obras de arte contemporânea, em meio a suas afasias (FREIRE, 2005: 65), constituem as reflexões na presente proposta como dispositivos e processos que problematizam o tempo-espaço pois, a instabilidade causada por algumas obras institucionalizadas instaura novas formas às ações dos museus.

Entre as diferentes possibilidades das linguagens da arte contemporânea, a escolha aqui recai sobre a performance por sua causalidade, transgressão, (re)apresentação e por seu caráter, sobretudo, efêmero. Afinal, como pensar na institucionalização de obras que carregam consigo uma determinada duração? $O$ que efetivamente os museus tem adquirido de performances que ocorreram em seus espaços ou fora deles? Como os vestígios são (re)apresentados e recepcionados pelos públicos? Como a partir dos fragmentos memoriais as obras são reperformadas? São reperformadas?

As questões apresentadas acima fazem parte das indagações frente algumas performances institucionalizadas ou ocorridas em outros espaços, a exemplo das obras: Palhaço com buzina reta monte de irônicos (2007) de Laura Lima, adquirida pelo Museu de Arte Moderna de São Paulo (MAMSP); e a Transmutação da Carne (2000) de Ayrson Heráclito, performada no Instituto Cultural Brasil Alemanha de Salvador-Bahia (ICBA) e no Serviço Social do Comércio de São Paulo (SESC-SP). 
Laura Lima ficou conhecida como a primeira artista no Brasil a ter performances adquiridas por um museu. Um aspecto interessante sobre a artista é que ela não denomina suas ações como performances. Laura Lima utiliza o termo instauração, a partir da leitura de uma entrevista de Tunga, pois o termo designa, segundo a artista:

"um processo que me parecia mais complexo do que focar no desempenho do performer [...]. Se a força da obra não é o sujeito, a ênfase se concentra no verbo, certo?" (LIMA apud LAGNADO; CASTRO, 2014: 31). No entanto, o museu trabalha com categorias estabelecidas pela crítica e pela história da arte, denominando a ação como performance. Outro aspecto é o fato das obras serem (re)performadas em diferentes exposições no museu com diferentes performers. Laura Lima orquestra e delimita as ações que são - serão - realizadas por outras pessoas.

Já a obra Transmutação da Carne de Ayrson Heráclito foi reperformada em alguns espaços, dentre eles o ICBA e o SESC-SP. Neste segundo espaço, a performance ocorreu como parte das ações da exposição Terra Comunal - Marina Abramović. A ação é considerada um evento polifônico com diversos desdobramentos do artista frente a sua poética, os espaços e os materiais a serem experimentados durante as ações. Ayrson Heráclito nas reperformações inclui citações das ações anteriores e institui novos elementos com ele performando e com outros performers.

Os dois casos escolhidos possibilitam encarar uma realidade plural das ações performáticas, causando reflexões sobre a institucionalização e a (re)apresentação das obras, e desafios aos museus, uma vez que é necessário estabelecer diálogos com os artistas, desenvolver narrativas a partir desses diálogos e dos vestígios memoriais, assim como promover conexões entre as poéticas e o público.

No primeiro caso, a institucionalização ocorre de forma a dialogar com os procedimentos detalhados pela artista, "[...] tem as tarefas, como fazer, e depois os museus vêm comprar a obra e eles têm um monte de regras que têm que seguir, porque senão aquilo não é a minha obra. Dou aquele modus operandi gigantesco, e não pode mudar nem uma coisinha se quer" (LIMA, 2010: 21), ainda que a obra esteja categorizada como performance. O museu é convidado a analisar as suas categorias e construir narrativas a partir dos vestígios e das instruções estabelecidas por Laura Lima.

No segundo caso, a reperformação de Transmutação da Carne pode levar o espectador ao passado, ao momento presente e a criação de possibilidades no futuro, por ser parte de um trabalho que vem sendo desenvolvido há anos, o que apresenta um elo entre as ações, e que também demonstra o caráter efêmero, pois são ações singulares realizadas em um determinado lugar com duração variável e com diferentes pessoas.

Nesta proposta, a percepção da pluralidade de performances constitui problematizações sobre a institucionalização dessas obras e a (re)criação de narrativas sobre os fragmentos memoriais oriundos da produção artística e dos momentos em que ocorreram. Assim, elaboram-se reflexões sobre a transitoriedade da ação; a materialidade existente, que engloba corpo e outras matérias; e, o caráter intangível das ações frente à efemeridade da singularidade das ações performáticas em determinado espaço com duração variável, cujas narrativas a serem propostas dialogam com a presença e a 
ausência de vestígios memoriais. $\bigcirc$ que possibilita também refletir sobre o caráter de arquivo ficcional nos museus conjugados nos tempos.

\section{Objetivos Geral e Específicos}

Compreender a institucionalização e as narrativas presentes e ausentes dos vestígios memoriais de performances nos museus. Seriam objetivos específicos: a) dialogar com os conceitos e definições de memória, tempo, performance relacionados a narrativas de performances institucionalizadas e dos museus; b) compreender as aquisições de performances nos museus; c) analisar a pluralidade de vestígios memoriais de performances institucionalizadas; e, d) compreender a constituição de narrativas a partir dos vestígios das performances institucionalizadas e a recepção do público.

$\underline{\text { Revisão da Literatura }}$

Quando acionado o dicionário, o termo fragmento é descrito como: "1. Pedaço de coisa quebrada; 2. Resto de coisa, derretida ou queimada em parte, etc; [...] 4. Resto" ; e o termo vestígio é descrito como: "1. Rastro; pegada; 2. Aquilo que fica ou sobra do que desapareceu ou passou". Para esta proposta os termos apresentados (re)significam as narrativas sobre as coisas, os objetos, as obras selecionadas e adquiridas em acervos museológicos, que são fragmentos de momentos e situações, vestígios tangíveis e intangíveis sob perspectivas de memórias individuais e partilhadas (re)construídas.

Esses termos apresentam, portanto, versões sobre a salvaguarda de acervos museológicos, indícios de culturas, práticas e ações que foram selecionados no intuito de representar os rastros e restos memoriais para a construção de narrativas em museus e a recepção dos públicos. Neste sentido, esta proposta tem o termo fragmento em seu título por ser significativo na análise da institucionalização de performances e de seus vestígios nos museus; mas também e fundamentalmente, pelas performances transgredirem as noções de memória e de tempo, no que tange a construção de narrativas nos museus. A performance como algo volátil em uma proposta de estudo de cultura material nas instituições, que pode ser absorvida pela tangibilidade dos vestígios, mas que tem a intangibilidade como fator determinante para a constituição de narrativas sobre os fragmentos.

A constituição de narrativas sobre os fragmentos revela a memória como ato de recordação e construção de lembranças. Fragmentos também são formas de reconhecimento de representações sobre culturas, práticas, ações individuais e coletivas, a partir da duração temporal do que é vivido em determinado espaço, e o caráter seletivo da memória, sendo o ato de lembrar também um dispositivo para o esquecimento.

Para Andreas Huyssen (2014: 158) "Esquecer não apenas torna a vida vivível, como constitui a base dos milagres e epifanias da própria memória". As performances experimentadas pelos públicos seja no 
momento em que ocorreram quanto na reprodução de vestígios sobre as ações e nas reperformances apresentam formas de acionar as memórias e os esquecimentos produzidos nas narrativas das instituições museológicas e na recepção do público. Evidenciando, assim, que a memória é seletiva, uma vez que são feitos recortes - enquadramentos - sobre o que se quer comunicar, e ficcional, pois é compartilhada e recriada sobre pontos de vistas individuais e partilhados, que significam múltiplas realidades.

Segundo Joël Candau (2005: 22), "a memória não é pois um processo passivo de armazenagem: ela é plástica, flexível, flutuante, de uma grande capacidade adaptativa e variável de um indivíduo a outro", a sua competência "[...] só é possível a partir das interações sociais e culturais" (CANDAU, 2005: 25). Neste sentido, o museu - extensão da memória de indivíduos e grupos sociais - é analisado aqui como uma instituição que comunica memórias e salvaguarda fragmentos sobre as performances, cujos vestígios memoriais possuem usos na produção de narrativas, que são parte de uma memória institucional armazenada, mas também parte da constituição de narrativas que demandam adaptação frente aquilo que será selecionado e representativo na (re)apresentação para os públicos.

Nesta mesma linha, Michel Pollak (1989: 3) afirma que a memória é constituída e formalizada a partir de seleções para a (re)criação de narrativas que podem viabilizar referências e enquadramentos das representatividades e que retratam a duração de ações a partir dos vieses da legitimação. $O$ museu como lugar de memória, diferente do lugar de memória proposto por Pierre Nora (1981) como o lugar que pára o tempo, seria onde narrativas sobre as memórias são selecionadas e relacionadas a representatividades das - nas - sociedades (CANDAU, 2005: 63). Estas narrativas são processuais por seu caráter de transformação frente as demandas culturais, sociais, políticas e econômicas.

Nesta escrita, os museus como extensões de memórias partilhadas são variações de memórias individuais (CANDAU, 2005: 90-91). No caso de performances, os fragmentos são selecionados e adquiridos a partir da poética e dos documentos produzidos pelo artista, da experiência do público, e do que - como - foi coletado pelas instituições, gerando recordações que estão pautadas na absorção das memórias individuais, que também geram ausências - esquecimento: "[...] o trabalho da memória consiste precisamente em esquecer certos acontecimentos para privilegiar outros" (CANDAU, 2005: 120). Este aspecto define as práticas seletivas dos museus frente aos vestígios memoriais, gerando presenças e ausências, com ideias perenes sobre a fixação das coisas e dos tempos, criando uma ficção sobre o caráter de longa duração dos fragmentos. Neste sentido, a performance é aqui escolhida como uma linguagem que transgride o caráter de uma memória fixa e perene, uma memória que se constitui conforme a produção artística e o acontecimento no espaço e na recepção do público, sendo esta memória um dispositivo particular e com vieses múltiplos de interpretação para a salvaguarda e comunicação.

Segundo Roselee Goldberg (2015: 8), a performance é uma expressão artística desde os futuristas até os dias atuais, que visa se dirigir "[...] diretamente a um grande público, bem como de chocar as plateias, levando-as a reavaliar suas concepções de arte e sua relação com a cultura". Esta relação com o público é latente, pois envolve a participação em ações inusitadas e transgressoras (GOLDBERG, 2015: 8), sendo a performance caracterizada como uma ação fugaz (MELIM, 2008: 64). Por exemplo, 
a obra, Como explicar imagens a uma lebre morta (1965) de Joseph Beuys, citada pela autora Goldberg (2015: 140) pode ser analisada a partir dos registros (fotografias, vídeos, entrevistas e escritos do artista). A obra em questão tem caráter efêmero, pois ocorreu durante três horas na galeria Schmela, em Düsseldorf - Alemanha, cuja participação do público ocorreu pelas janelas da galeria.

Os vestígios desta performance como de outras realizadas pelo artista são comunicados e reproduzidos em vídeos, fotografias e exposições sobre Joseph Beuys, como memória construída sobre as ações. A questão da reprodução dos vestígios apresenta a transitoriedade da ação, mas também evidencia possibilidades de transformação dos vestígios em novas obras e a sua incorporação nos acervos arquivísticos e museológicos.

A performance é analisada no museu por seu caráter efêmero e por suas formas de (re)apresentação como acervo museológico e - ou - como vestígios de ações que ocorreram em seu espaço a partir da produção documental dos artistas e de suas poéticas, da recepção do público e da produção de sentidos da crítica e da história arte. Segundo Amelie Jones (2011), os estudos sobre a performance causam a história da arte questões complexas, tendo em vista que são ações únicas em um determinado espaço-tempo, fundamentalmente, quando as ações ou os seus vestígios memoriais são (re)apresentados. Para a autora, lidar com a performance é compreender o caráter memorial complexo das ações como um processo de representação da memória frente as experiências do corpo e da mente entre o tempo passado, presente e futuro (JONES, 2011 : 33).

Diante das afasias da arte contemporânea e das diferentes poéticas dos artistas, a performance transgride o fixo e as predeterminações de uma narrativa linear sobre as obras, o fato de serem ações únicas mesmo quando reperformadas evidenciam as citações entre ações passadas, 0 momento presente e os desdobramentos na conjugação dos tempos da poética dos artistas. Dialogam assim, com uma ideia extensiva da memória e dos esquecimentos causados pelas escolhas e ausências dos elementos utilizados anteriormente e a incorporação de novos elementos.

Dentre as formas de comunicação de performances, Robert Morgan, no texto Thoughts on reperformance, experience, and archivism (2010), discute a reperformance de ações, a exemplo de Seven Easy Pieces, onde Marina Abramović reperforma cinco obras de outros artistas, Bruce Nauman, Vito Acconci, Valie Export, Gina Pane e Joseph Beuys (MORGAN, 2010: 11), com base nos desdobramentos das leituras dos registros das obras. A partir das experiências e do arquivamento dos vestígios das performances, Morgan apresenta reflexões sobre escolhas dos usos desses arquivos e do que se espera arquivar, e as possibilidades em salvaguardar esses registros para experiências futuras, que viabilizam a reapresentação de ações pelo mesmo artista ou por outros artistas, performers e a recepção dos públicos nos museus.

Para Catherine Millet (1997: 77), o museu é dinâmico, cria possibilidades de fixar a instabilidade de obras de arte contemporânea, pois encontra formas de preservá-las, tendo em vista as possibilidades de ressignificação. Ou seja, o museu é processual, as suas práticas são transformadas conforme as demandas da sociedade e o desenvolvimento da produção artística e de outras produções de sentidos, mesmo obras que apresentem a não perenidade - a efemeridade em sua poética - como performances institucionalizadas. 
A institucionalização tem como sinônimo a musealização, termo utilizado no campo do conhecimento da museologia, que significa a incorporação de uma referência cultural em espaços como museus. Segundo André Desvallées e François Mairesse (2013: 57), a musealização “[...] é a operação de extração, física e conceitual, de uma coisa de seu meio natural ou cultural de origem [...]" e causa mudança no estatuto do objeto, quando incorporado ao acervo de museu "[...] assume o papel de evidência material e imaterial do homem e do seu meio, e uma fonte de estudo e de exibição, adquirindo, assim, uma realidade cultural específica" (DESVALLÉES; MAIRESSE, 2013: 57).

No entanto, esta retirada da referência cultural e dos vestígios que the representam de um contexto não se aplica literalmente a arte contemporânea, a exemplo de performance, que pode ser institucionalizada como um acontecimento dentro ou fora do museu, reperformada e os seus vestígios podem ser incorporados e apresentados em outras mídias. Evidentemente, que existem os contextos dos artistas e do acontecimento da obra, e o fato da obra ser institucionalizada, legitima a produção artística, arquiva as experiências de um determinado momento, cria perspectivas para a produção de pesquisas e afirma o museu como um espaço experimental para ações e situações geradas por diferentes linguagens e poéticas. Walter Zanini, em sua experiência como diretor do Museu de Arte Contemporânea da Universidade de São Paulo (MAC-USP), afirma que o museu de arte se transforma em instituição de contato direto com o ato criador e de participação ativa de todos os envolvidos, os profissionais de museus, os artistas e o público (ZANINI, 2010: 59).

Para além da alteração das perspectivas dos modos de atuação da instituição e da participação de artistas e do público na zona interna dos museus, alguns artistas consideram fundamental a institucionalização de suas obras como forma de legitimar a própria produção e o museu como lugar ideal para a salvaguarda das obras e dos vestígios sobre as obras.

Um exemplo é o relato do artista Cildo Meireles, que em algum momento precisou de informações sobre a sua obra, Eureka (1970-1975), e teve acesso aos documentos e registros realizados pela Tate Modern, em Londres:

Foi quando me convenci de vez que os bons museus são o melhor destino para os trabalhos de arte. Porque o museu, além de exibir e estudar a obra, tem por obrigação cuidar da peça, climatizar o espaço onde ela fica. Aqui no me ateliê não posso pensar em climatizar, seria muito caro. São raros os artistas que podem manter seus trabalhos em condições museológicas de armazenamento. O museu favorece a acessibilidade para pesquisa e empresta para outras exposições do artista. Hoje em dia, o museu é a maneira mais respeitosa de o artista tornar sua obra acessível ao público (MEIRELES, 2014: 110).

Para esta proposta, a possibilidade de tornar obras acessíveis como salienta Cildo Meireles ocorre por meio da aquisição e da realização de registros sobre a obra pelos profissionais dos museus, assim como pelos artistas. Segundo Anne Bénichou (2013: 172), "[...] a documentação que os artistas estabelecem sobre suas obras constitui vestígios delas, que [...] atesta sua existência e as instrui", 
METAgraphias: letra E (sobre errância e-Rancièrráticas) v.2 n.2 junho| 2017 fragmentos [vestígios] memoriais de performance nos museus•Anna Paula da Silva (annapaulasilva.86@gmail.com)

documentação essa considerada pela autora híbrida e processual por apresentar a documentação da obra e a própria obra (BÉNICHOU, 2013: 172).

Os vestígios memoriais, em forma de registros, são partes fragmentadas das obras, criando possibilidades de arquivo, criação de novas obras e (re)apresentação das performances e reperformances. Segundo Anne Bénichou (2013: 179), a performance só poderá ser (re)acionada a partir dos seus registros e documentos como dossiês e memoriais sobre a obra disponibilizados pelos artistas. Nesta mesma linha de raciocínio, Luiz Cláudio da Costa (2009: 89) apresenta a relevância do registro, pois promove a circulação de vestígios memoriais das obras, que venham - ou não - a desaparecer, e alimentam o arquivo institucional, viabilizando a comunicação dessas referências, como também os desdobramentos do sentido poético singular da existência da obra.

Os registros das - e sobre as - obras revelam as redes de conexão entre contexto do artista, contexto da instituição, recepção do público e as dobras possíveis da obra, como Laura Lima na transcrição detalhada dos procedimentos sobre a realização das performances adquiridas no MAM-SP; e Ayrson Heráclito com a reperformance, A Transmutação da Carne, em diferentes tempos e espaços, com citações de suas memórias das ações passadas a partir dos vestígios, vídeos, fotografias e escritos do artista.

No texto The performativity of performance documentation, Philip Auslander (2006) analisa a representação das ações de artistas a partir dos registros de performances e as leituras sobre a produção artística, utilizando duas categorias: teatral, registros que apresentam a performance no tempo e no espaço com a participação do público; e documental, registros de ações que não foram apresentadas ao vivo. Em sua análise, as ações que englobam as duas categorias são consideradas performances. Para o Auslander (2006: 9), é necessário rever o sentido de presença ao analisar o registro, o documento da performance como um meio de acessar o passado, mas também como um documento que direciona para reflexões sobre a poética do artista, aciona a sensibilidade na recepção do público e a compreensão da linguagem em diferentes perspectivas.

Algumas obras apresentam processos de reinterpretação e reativação dos sentidos a partir dos seus vestígios, a exemplo da obra Grapefruit (1964) de Yoko Ono " [...] com cento e cinquenta instruções de trabalhos, divididos em cinco sessões: música, pintura, evento, poesia e objeto. Em 2000, uma nova edição é publicada acrescida de oitenta instruções e duas outras sessões: filme e dança" (MELIM, 2013: 26). Esse trabalho apresenta a possibilidade de uma performance colaborativa e interativa realizada pelo público a partir das instruções da artista, ou seja, o público torna-se autor da ação.

A performance como uma linguagem que viabiliza a participação do público seja por uma ação ocorrida em um determinado espaço-tempo; uma performance filmada - fotografada - em um espaço sem a presença de um público; uma reperformance; uma ação do tempo passado de um artista reperformada por outro artista; como também ações que oferecem instruções ao público podem ser institucionalizadas nos museus a partir dos vestígios memoriais. A institucionalização nos museus ocorre para a formação de acervo, que contempla campos do conhecimento como a museologia e a história da arte, e esta formação está aliada a função social do museu frente a recepção dos públicos. 
Neste sentido, o público é essencial para a compreensão da recepção de obras institucionalizadas, a partir do olhar e da relação estabelecida com a poética e com as narrativas curatoriais da instituição. O contexto institucional apresenta memórias sobre as obras, o artista e a própria instituição, o público é convidado a interagir com as memórias ali apresentadas e constituir as suas próprias memórias sob os vestígios memoriais apresentados pelo museu.

A performance como expressão artística apresenta-se com proposições para um público emancipado, que não experimenta a obra de forma passiva, mas que aprende, ensina, age, conhece, que se relaciona com o que vê (RANClÈRE, 2012: 21). Portanto, a institucionalização dos vestígios memoriais sobre performances dimensiona ao público uma participação ativa nas memórias (re)construídas e narradas nos museus.

Metodologia

Esta proposta de pesquisa é exploratória, pois visa compreender a institucionalização de performances e dos seus vestígios nos museus, a partir do contato com a realidade de instituições, que tenham em seus acervos performances e - ou - os seus vestígios memoriais, ou que tenham sido espaço de acontecimentos de alguma ação, e os desdobramentos temporais e institucionais das obras; o contato com profissionais de museus, que possam abordar o modus operandi no desenvolvimento de comunicação, pesquisa e preservação desse tipo de linguagem nos acervos; e artistas que desenvolvam performances, cuja poética possa ser analisada sob elementos de duração, perecibilidade e efemeridade.

Esta pesquisa tem abordagem qualitativa, pois visa constituir reflexões sobre as institucionalizações de performances, apresentando o histórico nos museus brasileiros e algumas referências de museus em outros países. Para tanto, será realizada revisão teórica sobre performance, memória e tempo, a partir de pressupostos da crítica, história da arte, museologia, história, filosofia, tendo em vista compreender - espaço-tempo no museu e o desenvolvimento de narrativas a partir dos vestígios memoriais sobre as performances e a (re)apresentação de (re)performances; a pesquisa de campo em museus, para compreender as aquisições de performances e a pluralidade de vestígios memoriais, tendo como base a pesquisa documental sob os registros oriundos da documentação museológica realizada pelas instituições, assim como informações sobre a recepção do público; e entrevistas semiestruturadas com profissionais de museus - curadores, museólogos, conservadores, historiadores, etc. - e artistas, como um procedimento de análise de discurso e da constituição de memórias individuais e partilhadas sobre obras institucionalizadas.

A proposta também vislumbra o pensamento visual como forma de análise que qualifica a pesquisa de - sobre - arte aliada "[...] à sensibilidade do olhar, a profundidade da formação teórica" (CATTANI, 2002: 38), produzindo conhecimento a partir de análises sobre a visualidade, os processos dos artistas, - processo das obras nos museus, assim como a recepção da obra para compreender a institucionalização de performances nos museus. 
METAgraphias: letra E (sobre errância e-Rancièrráticas) v.2 n.2 junho| 2017 fragmentos [vestígios] memoriais de performance nos museus • Anna Paula da Silva (annapaulasilva.86@gmail.com)

$\underline{\text { Referências Bibliográficas }}$

AUSLANDER, Philip. The performativity of performance documentation. PAJ 84. 2006, p. 1-10.

BÉNICHOU, Anne. Esses documentos que são também obras. Revista-Valise. Porto Alegre, v. 3, n. 6, ano 3, dez. 2013, p. $171-191$.

CANDAU, Joël. Antropologia da memória. Lisboa: Portugal: Armand Collin / Instituto Piaget, 2005.

CATTANI, Iclea Borsa. Arte contemporânea: o lugar da pesquisa. In: BRITES, Blanca; TESSLER, Elida. O meio como ponto zero: metodologia da pesquisa em artes plásticas. Porto Alegre: Editora da Universidade Federal do Rio Grande do Sul, 2002 , p. 35-50.

COSTA, Luiz Cláudio da. O registro na arte contemporânea: inscrições de visibilidades, discursos e temporalidades como séries da obra. In: FAPERJ, 2009, p. 79-96.

DESVALÉES, André; MAIRESSE, François (Ed.). Conceitos-chave de Museologia. São Paulo: Comitê Brasileiro do Conselho Internacional de Museus / Pinacoteca do Estado de São Paulo / Secretaria de Estado da Cultura, 2013.

FREIRE, Cristina. Afasias na Crítica de Arte Contemporânea. In: GONÇALVES, Lisbeth Rebollo; FABRIS, Annatereza. Os lugares da crítica de arte. São Paulo: ABCA: Imprensa Oficial do Estado, 2005, p. 63-76.

GOLDBERG, Roselee. A arte da performance: do futurismo ao presente. 3 ed. São Paulo: Martins Fontes - selo Martins, 2015.

HUYSSEN, Andreas. Resistência à memória: usos e abusos do esquecimento público. In: Culturas do passadopresente: modernismo, artes visuais, políticas da memória. Rio de Janeiro: Contraponto / Museu de Arte do Rio, 2014 , p. $155-176$.

JONES, Amelia. Performance, live or dead. Art Journal. vol 70, n. 3, p. 33-38.

LAGNADO, Lisette; CASTRO, Daniela. Laura Lima on_off. Rio de Janeiro: Cobogó, 2014.

LIMA, Laura. Eu nunca ensaio: Entrevista. Arte \& Ensaios. Revista do PPGAV/EBA/UFRJ. n. 21, dez. 2010.

MEIRELES, Cildo. Criação de Valor: Entrevista. In: O valor da obra de arte. São Paulo: Metalivros, 2014, p. $100-135$.

MELIM, Regina. Performance nas artes visuais. Rio de Janeiro: Jorge Zahar ed., 2008.

MELIM, Regina. Performances impressas. Poiésis. n. 21 -22, jul. /dez. 2013, p. 25-30.

MILLET, Catherine. A Arte Contemporânea. Lisboa: Portugal: Flamarion / Instituto Piaget, 1997.

MORGAN, Robert C. Thoughts on re-performance, experience, and archivism. PAJ 96. 201 1, p. 1-15

NORA, Pierre. Entre memória e história: a problemática dos lugares. Projeto História. Revista do Programa de Estudos PósGraduados em História e do Departamento de História da PUC-SP (Pontifícia Universidade Católica de São Paulo). São Paulo, 1981.

POLLAK, Michel. Memória, Esquecimento e Silêncio. Estudos Históricos. Rio de Janeiro, vol 2, n. 3, 1989, p. 3-15.

RANCIÈRE, Jacques. O espectador emancipado. São Paulo: Editora WMG Martins Fontes, 2012. 
METAgraphias: letra E (sobre errância e-Rancièrráticas) v.2 n.2 junho| 2017 fragmentos [vestígios] memoriais de performance nos museus • Anna Paula da Silva (annapaulasilva.86@gmail.com)

ZANINI, Walter. Novo comportamento do Museu de Arte Contemporânea. In: RAMOS, Alexandre Dias (Org.). Sobre o ofício do curador. Porto Alegre: Zouk, 2010, p. 59-64. 